\title{
Los soportes de madera en esculturas policromadas mexicanas, restauradas
}

\author{
en la ENCRyM \\ Gabriela Cruz Chagoyán \\ Lilia Patricia Olvera Coronel \\ Irais Velasco Figueroa
}

( esde su llegada al continente americano, los españoles trajeron esculturas de madera policromada manufacturadas en Europa; $y$, una vez establecido el régimen colonial, importaron la tecnología, las estructuras gremiales y las ordenanzas que prevalecían en España en el siglo XVI. Sin embargo, esta tecnología se adaptó a la disponibilidad de materias primas en la Nueva España, incorporando el uso de maderas locales como soporte de las esculturas policromadas (Maquívar 1994: 301-325). De igual manera ciertas tecnologías prehispánicas fueron adaptadas para producir esculturas al estilo español, como es el caso de la caña de maíz empleada para producir esculturas ligeras (Amador 2002: 25).

No hay material más noble y más gratificante para los sentidos que la madera. Es una de las materias primas más antiguas utilizadas por el hombre, quien la ha empleado como combustible, cobijo, cuna, ataúd, arma, recurso cultural entre otros. La historia del uso de la madera se encuentra íntimamente vinculada a la historia de la humanidad, aparece constantemente en el acontecer de sociedades, pueblos y naciones, aportando un matiz particular al devenir de la cultura y sus productos. La madera presenta magníficas posibilidades de transformación, como puede observarse en la manufactura de diversos bienes culturales y en la trascendencia de su uso continuo. Por ejemplo, la pintura de caballete sobre tabla se utilizó desde la Grecia antigua y la civilización egipcia; su uso se generalizó desde el siglo XI y mostró su mayor auge, en los siglos XV y XVI (Gómez 2002: 22). Otro ejemplo lo proporcionan las esculturas policromadas tema central de nuestro estudio, en las cuales la talla está directamente relacionada con las dimensiones de los troncos, los cuales determinan el tamaño de la escultura. Sin embargo, en ocasiones, es posible encontrar ejemplares donde se observan varios embones, los cuales pueden estar ensamblados, pegados o clavados, con lo que se logran las formas y dimensiones requeridas en cada caso. En estas esculturas, es importante que el análisis sea preciso, para identificar las diversas especies de maderas utilizadas en distintas partes de la obra.

La información anterior es fundamental para el restaurador, por dos razones. En primer lugar, ciertos deterioros presentes en una escultura pueden ser atribuidos a causas intrínsecas, es decir, al empleo de diferentes maderas con distintas propiedades de densidad, absorción de humedad, contenido de resinas, etcétera; que ocasionen respuestas diferenciales en distintas partes de un mismo objeto. Algunas maderas son más sensibles a ciertas condiciones ambientales que pueden generar grietas o roturas del soporte, otras son más susceptibles al 
ataque de insectos o microorganismos. En segundo lugar, ante la necesidad de reponer faltantes de soporte, el restaurador debe tener información confiable sobre el tipo de madera utilizada, de manera que pueda elegir una con características similares a la original, para reconstruir los elementos faltantes.

Por otro lado, la gran cantidad de información que se ha generado mediante esta investigación, se integrará al conocimiento de los materiales empleados en la manufactura de las esculturas, a través del registro de nuevas especies y de su correlación con las maderas mencionadas en la documentación histórica. Estos datos también pueden ser de gran utilidad para los historiadores del arte, ya que el uso de ciertas maderas podría estar asociado a determinadas localidades, estilos, escuelas o autores en diferentes épocas que van desde el siglo XVI hasta el XX.

Es importante mencionar que este artículo muestra los resultados parciales de la investigación, a partir de los cuales se van generando nuevas líneas de avance. Por ejemplo, se ha creado una base de datos que se complementa semestre a semestre, con las maderas identificadas de cada escultura trabajada en el Seminario-Taller de Restauración de Escultura Policromada (STREP) de la ENCRyM; y que contiene los datos necesarios para la localización de los informes en la biblioteca. Estos materiales están disponibles para que cualquier investigador de otras áreas de estudio, pueda descubrir relaciones entre los materiales, las temporalidades y la localización de las esculturas policromadas, ${ }^{1}$ con el fin de construir el conocimiento de manera interdisciplinaria.

\section{Antecedentes}

Actualmente en las fuentes bibliográficas es escasa la información referente a las maderas empleadas en la manufactura de esculturas en Nueva España y México independiente. Existen estudios sobre algunas obras en particular, en donde se identificaron las maderas; como se puede constatar en las obras de Maquívar (1995) y Rojas (1963), que hacen referencia a la talla en madera; otros autores como Esquitín y Silva (1983) y Gómez (2002) hacen una pequeña semblanza de la utilización de este material para la elaboración de esculturas policromadas y para pintura de caballete. Una de las fuentes más importantes es de Carrillo y Gariel (1946), aunque no trata específicamente de escultura, sino que se refiere básicamente a pintura de caballete, proporciona datos muy importantes sobre las diversas especies de maderas utilizadas como soporte en la técnica de la pintura de caballete de la Nueva España.

También se tomó en cuenta la documentación bibliográfica en la cual se mencionan las maderas para manufactura de retablos, como el caso de Herrera (2001) y Vidal

1 Las esculturas con las que se trabajó en esta investigación, provienen de diversos ámbitos, como museos, templos y comunidades, localizados en diferentes lugares de la República Mexicana, que solicitan a la ENCRyM la restauración de su patrimonio
(2005). En cuanto a la construcción, Torres (1895) es una de las personalidades más destacadas del siglo XIX, como ingeniero y arquitecto en el estudio de los materiales y procedimientos constructivos, mostrando en su obra la utilización de diversas especies de maderas.

A diferencia de la bibliografía consultada, este trabajo ofrece un estudio general, que abarca un gran número de piezas de varios lugares de la República Mexicana y de distintas temporalidades (siglos XVI-XX), lo cual permitió la sistematización estadística de los resultados obtenidos, dando pie para correlacionar el uso de la madera tanto por siglos como por localización geográfica.

\section{Objetivos}

Revisar, corroborar e identificar las muestras obtenidas de maderas constitutivas de esculturas mexicanas restauradas en el STREP, pertenecientes a diferentes temporalidades, para compararlas con las reportadas en la documentación histórica.

\section{Metodología}

Este estudio -realizado en el laboratorio de biología de la ENCRyM- se dividió en dos partes; en la primera se ordenaron y corroboraron un total 294 muestras pertenecientes a 106 esculturas, la mayoría de las cuales fueron elaboradas en el STREP en el periodo de 1998 al primer semestre de 2008.

En la segunda parte de este trabajo, con la colaboración de los alumnos, se realizó la toma de muestras; y posteriormente, se identificaron en el laboratorio de biología. En total se tomaron 125 muestras de 34 esculturas, durante el segundo semestre de 2008 hasta el primer semestre de 2010.

Es importante mencionar la complejidad del proceso que se efectúa para la identificación de materiales en bienes culturales. En el STREP cada obra es observada detalladamente con la ayuda de un lente de aumento (lupa 5X) en todas sus áreas posibles, con el fin de determinar el estado general en el que se encuentra, es decir, si fue realizada con uno o varios tipos de madera y/o si presenta biodeterioro. A partir de esta observación se puede ubicar de manera macroscópica la zona de toma de muestra; se hace un pequeño corte en la madera aproximadamente de 3 a $5 \mathrm{~mm}$, con ayuda de la lupa y un bisturí, procurando que la muestra se encuentre lo más libre posible de algún tipo de biodeterioro o alteración mecánica.

Se realizan cortes en las superficies de las muestras que correspondan a los tres planos característicos de la madera (transversal, tangencial y radial), con la finalidad de determinar la estructura para cada uno. Cabe mencionar que en algunos casos sólo fue posible la realización de un corte único, debido al deterioro o al tamaño de la muestra que se tomó. Obtenidos los cortes, se tiñen con verde-yodo y, una vez secos, se fijan con bálsamo de 
Canadá, para finalmente ser observados bajo el microscopio óptico (Zeiss, ICS Standard 25) con aumentos de 10X y 40X. Posteriormente, se hace un registro fotográfico con ayuda de una cámara digital (Canon Power Shot S70). A los datos obtenidos se les aunó la temporalidad de cada una de las piezas y posteriormente se elaboraron gráficas circulares con las cuales se pudieran observar las diferentes maderas utilizadas en cada siglo.

Para la identificación, es preciso analizar las estructuras anatómicas macroscópicas y microscópicas que presentan cada uno de los tres planos de la madera; y comparar las características de la muestra con las descripciones e imágenes encontradas en bibliografía especializada. ${ }^{2} \mathrm{Al}$ reconocer las estructuras que corresponden a angiosper- mas y gimnospermas la caracterización avanza hacia el análisis de la anatomía de la muestra, lo cual requiere experiencia para identificar las variantes de estructuras complejas, con lo que finalmente se puede identificar el género $y$, de ser posible, la especie de madera.

\section{Resultados}

En la Tabla 1, se pueden observar de manera descendente según su frecuencia el número de muestras identificadas de las maderas más utilizadas en la manufactura de esculturas, así como la imagen microscópica que muestra los elementos anatómicos, con los cuales fue posible su identificación.

\section{Tabla 1}

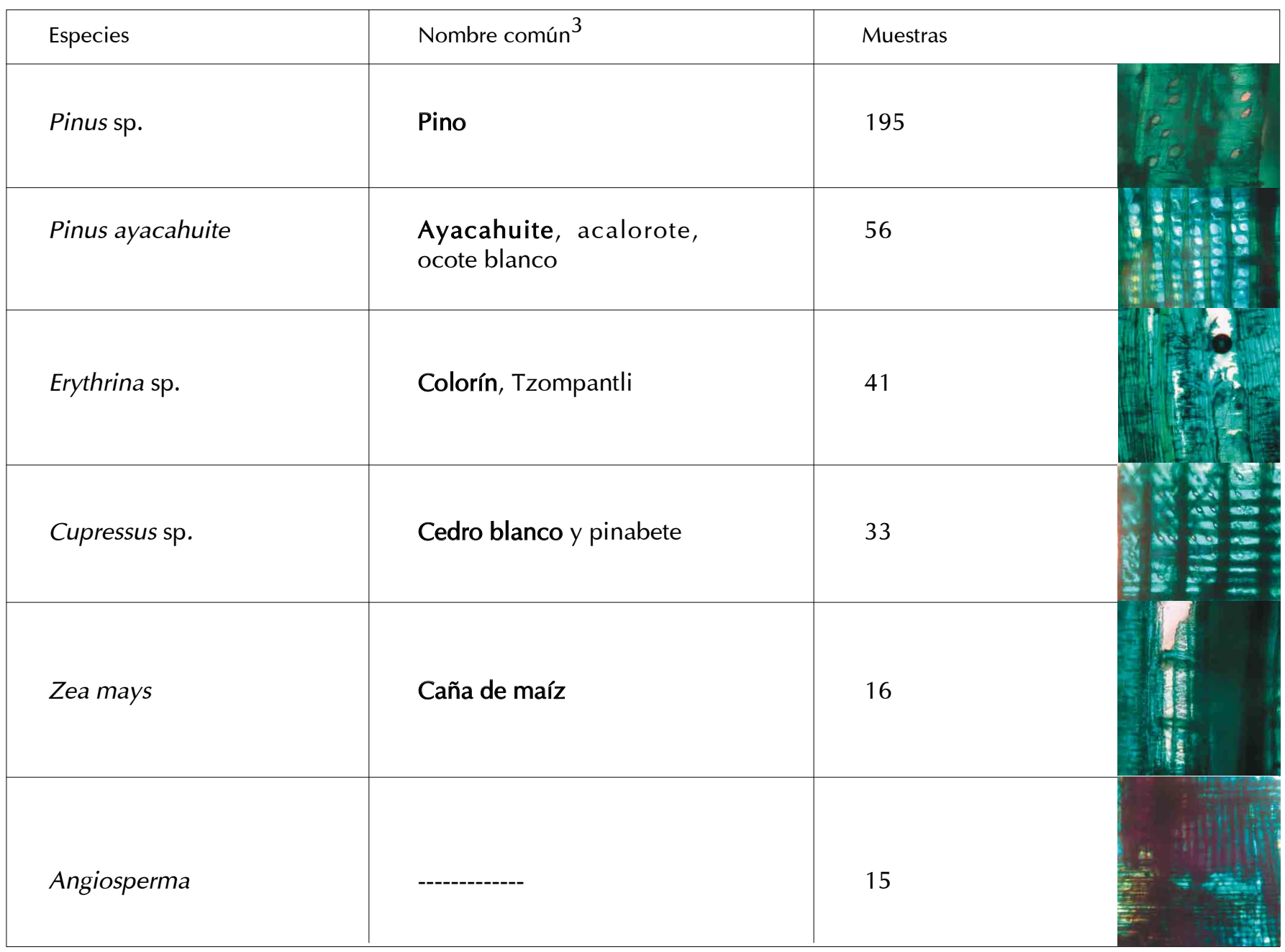

${ }^{2}$ Para este proceso se consultaron los boletines de fichas técnicas de instituciones de investigación forestal que describen las principales características macroscópicas y microscópicas por especie arbórea. Además se recurrió a la xiloteca que tiene el laboratorio de biología de la ENCRyM. Asimismo se revisaron los libros especializados de anatomía de madera, fisiología vegetal y preparación microscópica de madera patrón.
${ }^{3}$ Es importante mencionar que los nombres comunes para cada tipo de madera pueden variar dependiendo del estado de la República Mexicana. Se marcan con negritas los nombres más usuales, aunque se citan otros con los que se les pueden encontrar. La información se obtuvo de los boletines del Instituto Nacional de Investigaciones Forestales, Agrícolas y Pecuarias (ver bibliografía). 


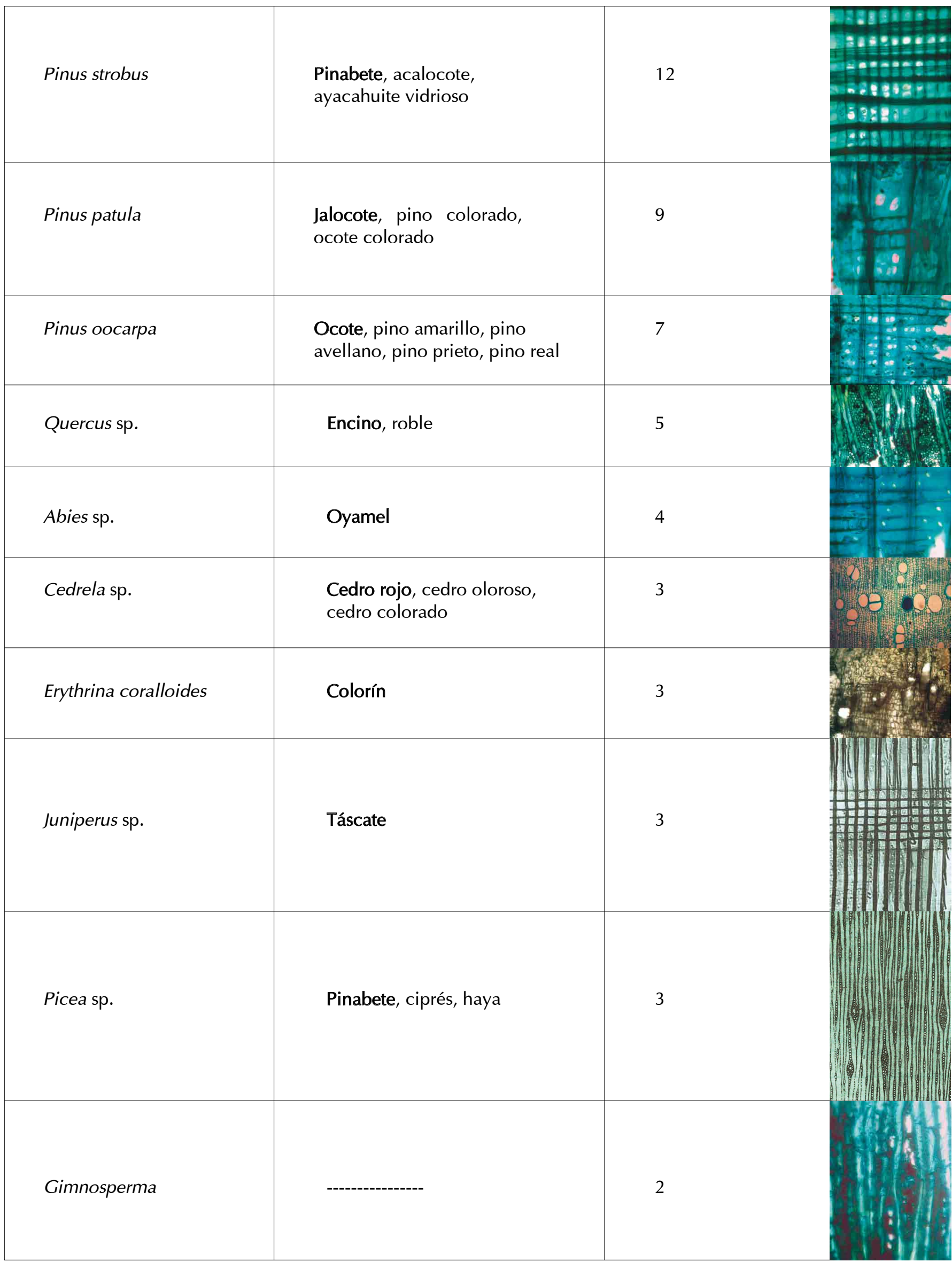




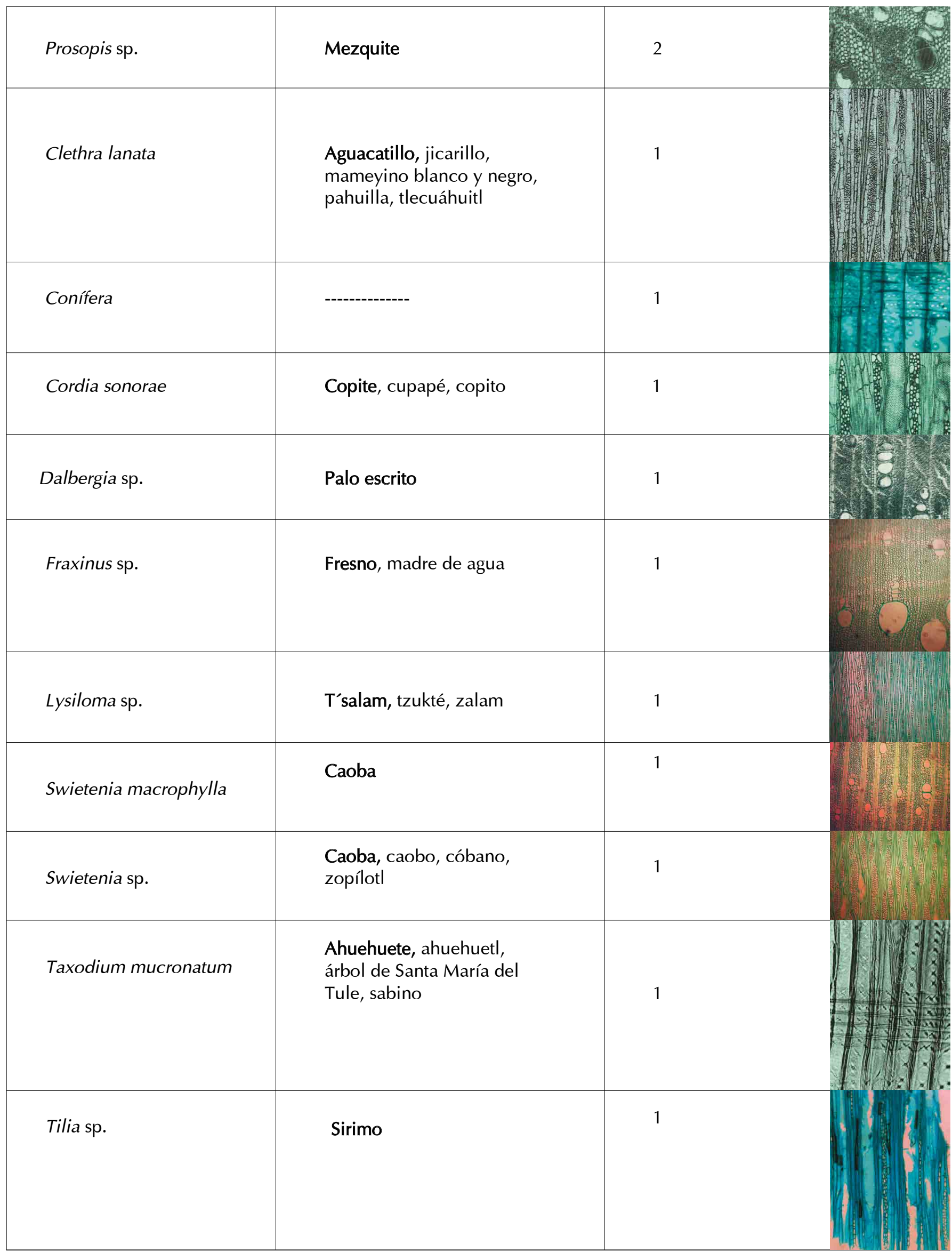


En la siguiente figura se muestra el ejemplo de una escultura en donde se observan las diferentes especies de maderas que fueron identificadas, con el fin de llevar a cabo la restauración en el STREP.

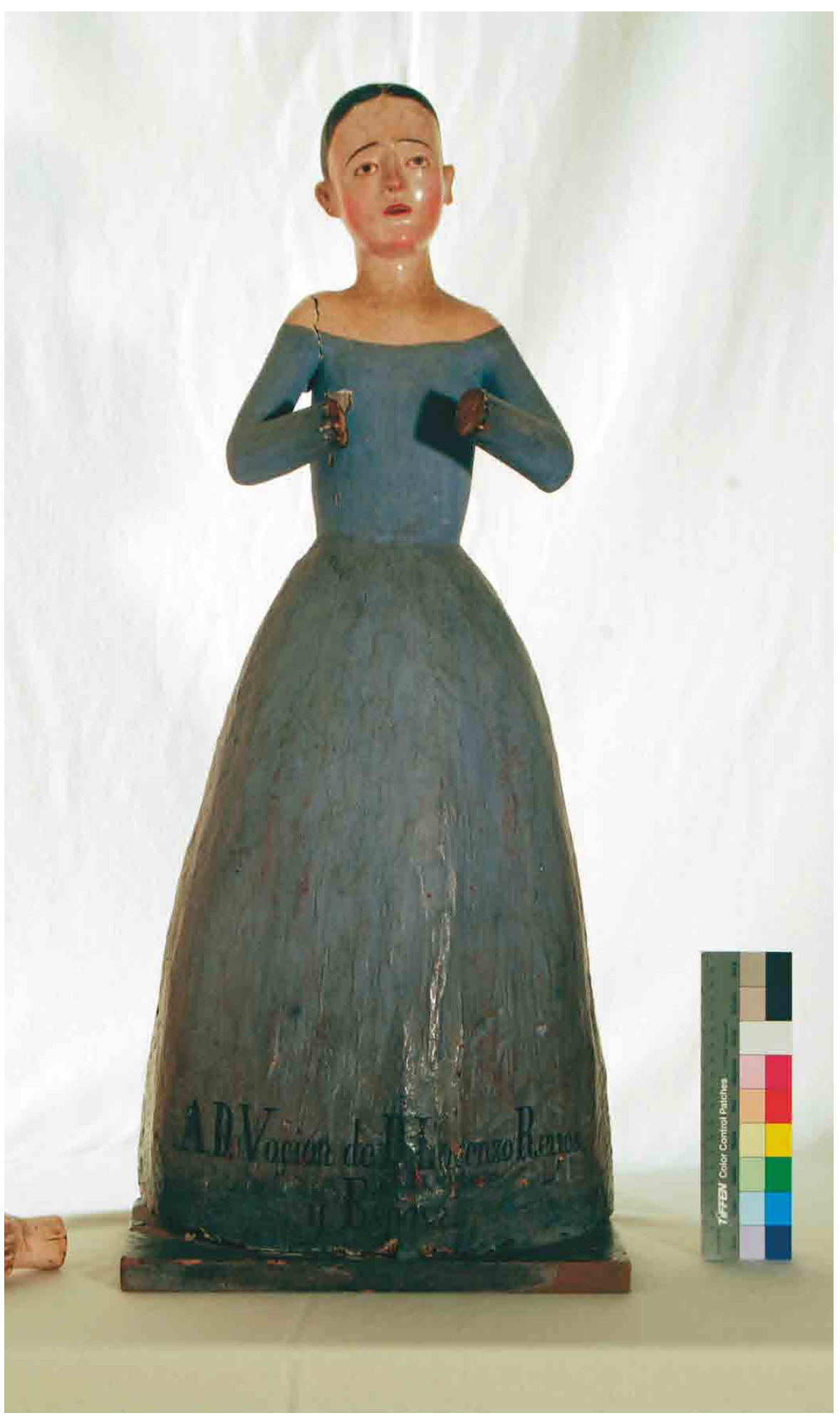

FIGURA. 1. Virgen de Dolores, (siglo xix). Museo de Sitio de Tupataro, Michoacán.

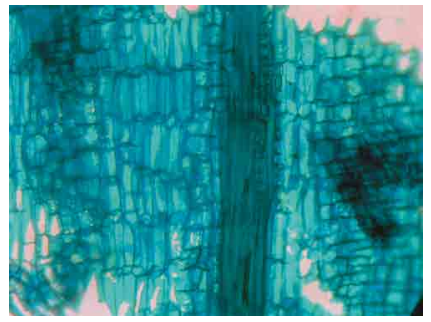

Erythrina sp

Cabeza

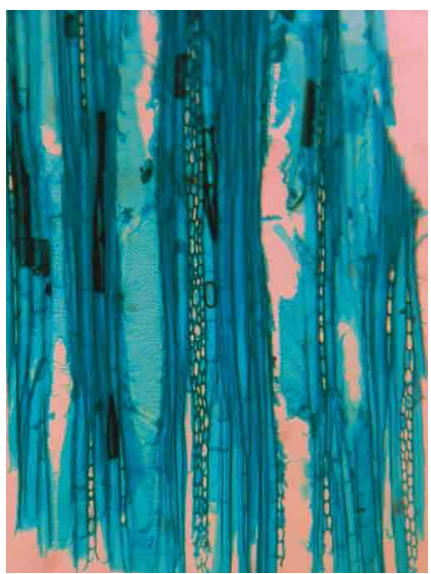

Tilia sp.

Manos

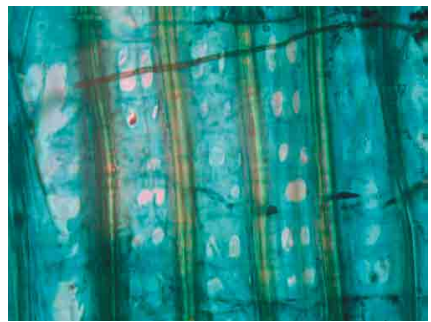

Pinus sp.

Cuerpo

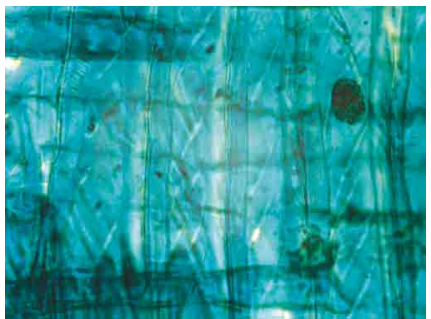

Cupressus sp.

Base de escultura 
En la Tabla 2, se presenta el número total de piezas que se trabajaron en el STREP de 1998 a 2010, de las cuales se tomaron muestras de madera para su iden- tificación, se presenta la temporalidad de cada una, los porcentajes y las gráficas correspondientes de las especies identificadas.

\section{Tabla 2}

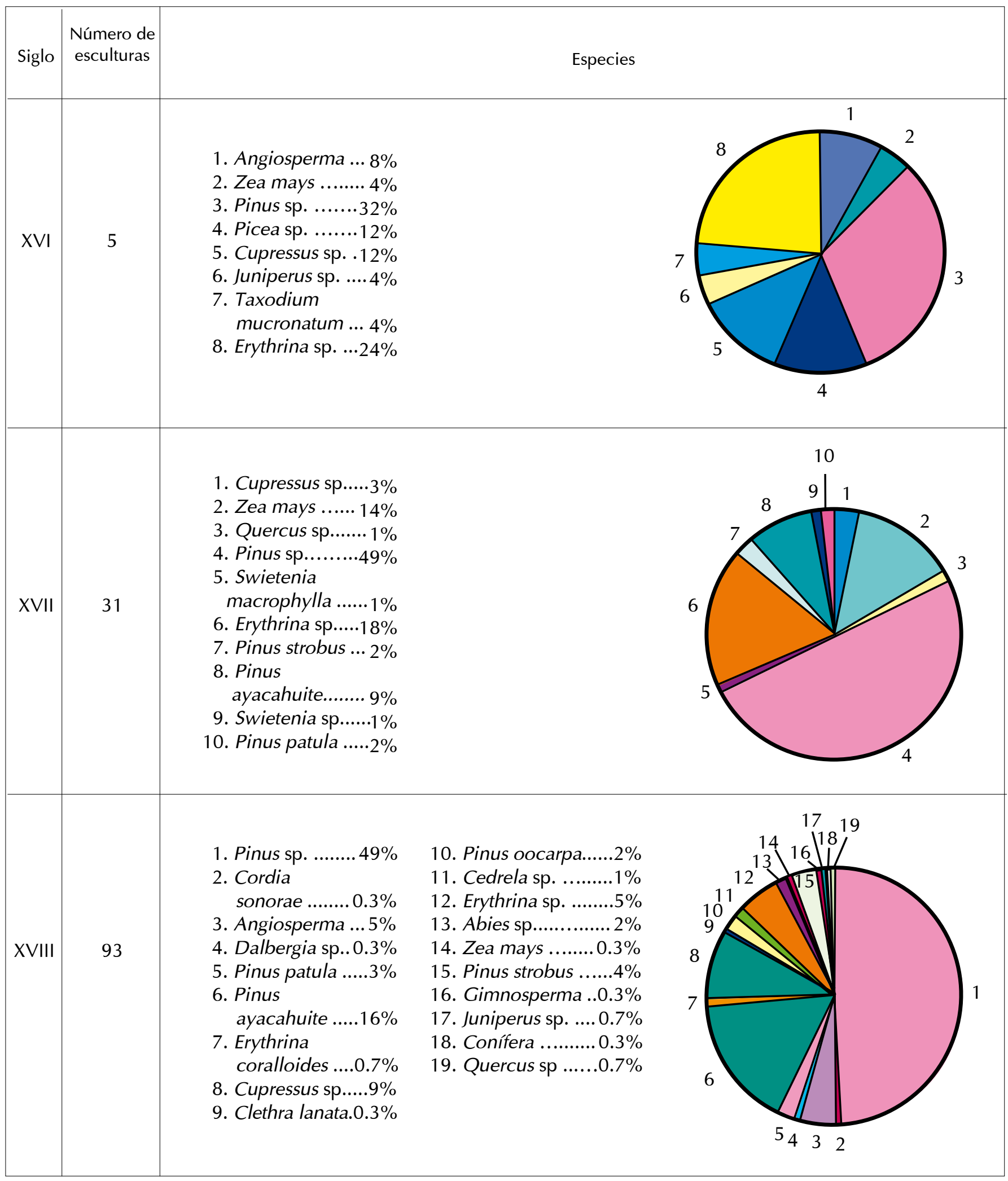




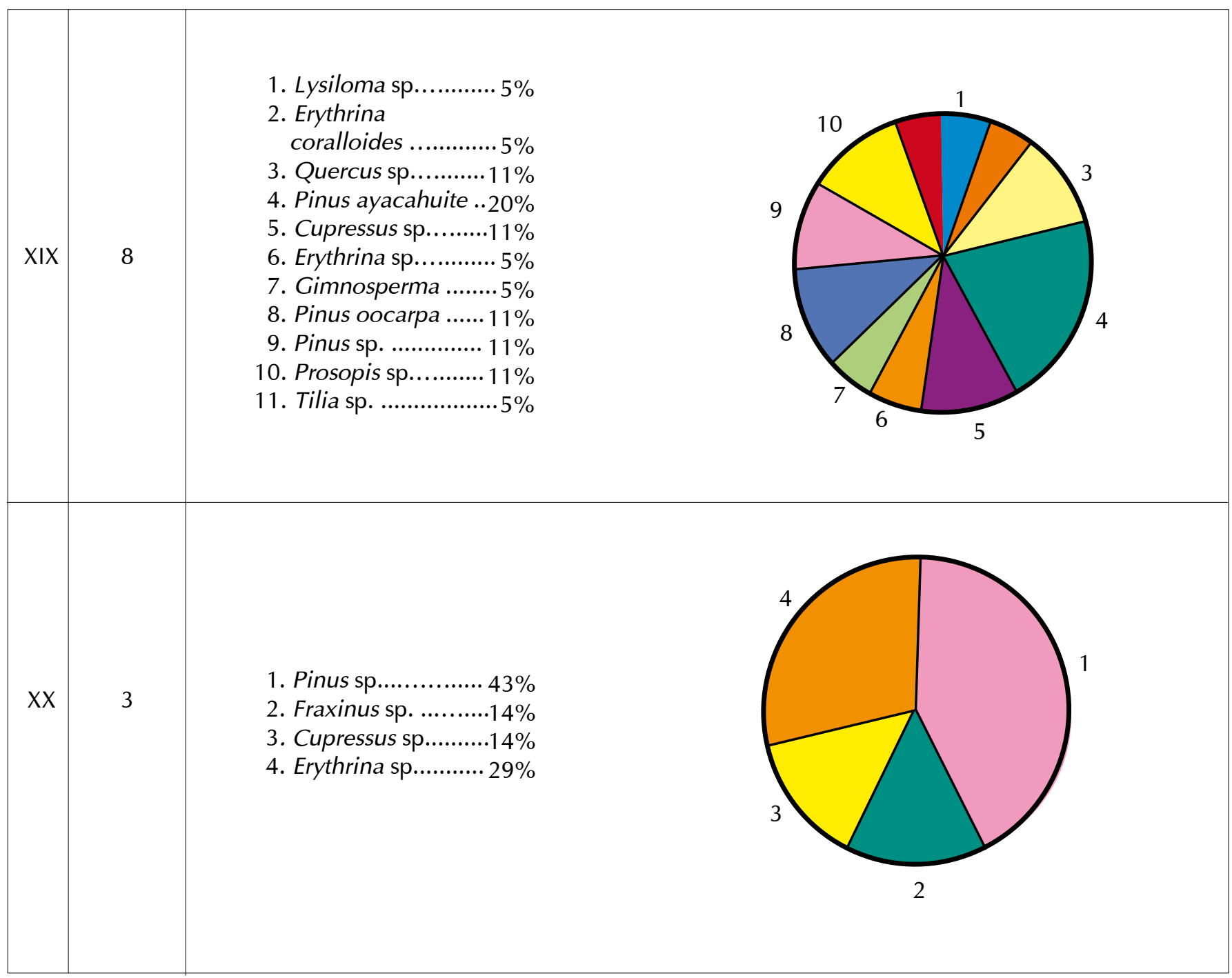

\section{Análisis de resultados}

Al agrupar las muestras de madera por época de producción de la escultura correspondiente es posible conocer, principalmente, cuáles eran las especies de madera más comunes en la manufactura de esculturas policromadas mexicanas. Maquívar (1995: 77 y 79) dice que las maderas de coníferas son las preferidas para tallar objetos, ya que sus células se encuentran en una estructura homogénea y están dispuestas longitudinalmente. Por otro lado, hace referencia a una cita de Esquitín y Silva (1983:121); en la cual, estos autores observaron que en la manufactura de imágenes, el corte más utilizado para esculpirlas era el longitudinal radial, ya que éste garantizaba "un bloque de madera más estable de los cambios dimensionales, además de ser más fácil el trabajo de corte y tallado".

Es evidente que desde el siglo XVI al XX, el uso del pino (Pinus sp.) (Tablas 1 y 2 ) es constante; Torres (1895: 51) menciona que el pino presenta una amplia distribución en la República Mexicana y que tiene características óp- timas para ser utilizado por los escultores, ya que posee una altura considerable, es recto (derecho) y soporta una mayor presión. Llama la atención el uso extensivo del $\mathrm{Pi}$ nus ayacahuite, a pesar de ser una madera resinosa (siglo XVII, 9\%; siglo XVII, 16\%; siglo XIX, 20\%). De hecho, es la especie que se ubica en segundo lugar en frecuencia total, habiéndose encontrado en 56 muestras. A partir del siglo XVIII (Tabla 2) se tienen registros de la utilización de otras especies que contienen menor cantidad de resina como son Pinus oocarpa y oyamel (Abies sp.) (Torres 1895: 51 y 52). En los resultados obtenidos en el laboratorio, es evidente que los pinos se presentan en todos los siglos, en cambio el Pinus ayacahuite se encontró desde el siglo XVII hasta el XIX; y el Cupressus sp. se identificó en muestras del XVI al XX. Éstas son las maderas que se presentan en mayor porcentaje y número, en las preparaciones y corresponden a la cita de Maquívar (1995: 91):

La preponderancia de dos tipos de madera: el cedro y el pino; de éstos en algunos casos pudo identificarse qué tipo específico era, como el cedro blanco, el ayacahuite 
y el oyamel [...] el cedro blanco fue una de las maderas

más utilizadas por los artistas novohispanos [...]

Es importante señalar que las muestras que reporta la autora, se obtuvieron de 24 esculturas del Museo Nacional del Virreinato.

En la bibliografía especializada consultada, Maquívar (1995: 77) hace referencia a la utilización de angiospermas, como el encino y otra que denomina la "madera mexicana, el colorín", describiéndola como suave y ligera. Del mismo modo, Rojas (1963:162) dice que la madera ligera que nombra Tzompantli (colorín), se utilizaba para esculturas destinadas a salir en procesiones, en contraste con las maderas duras que se usaban para imágenes fijas y que por lo tanto podrían ser más pesadas. Como se puede observar en la Tabla 1, el género Erythrina sp. (colorín), es la tercera especie más frecuente, después de los pinos; infiriendo que desde el siglo XVI fue de gran utilidad para la talla de esculturas, identificándose cinco piezas, correspondientes a 24\% de esta especie. El porcentaje disminuye en siglos subsiguientes, por ejemplo, en el siglo XVII, de 31 esculturas analizadas $18 \%$ de las muestras corresponden a colorín, mientras que en el siglo XVIII, aunque el número de esculturas se triplica, el porcentaje de muestras se reduce en $5 \%$. Se observa, entonces, que esta especie de origen americano constituye una adaptación tecnológica, para la cual se emplean materiales locales, en lugar de los materiales de tradición europea.

Otro material empleado para imágenes religiosas, sobre todo cristos, en la época virreinal, es la caña de maíz (Zea mays) cuyos antecedentes se remontan al periodo Precolombino, ya que es un material ligero con el cual se podían esculpir figuras de gran formato de muy bajo peso y fácilmente transportables. Como se puede observar en la Tabla 1, es la quinta especie más frecuente. Es importante recalcar que de cinco esculturas del siglo XVI, $4 \%$ corresponden a la caña de maíz. Para el siglo XVII se analizaron los soportes de 31 esculturas y la caña de maíz se encontró en $14 \%$ de las muestras. Para el siglo XVIII, a pesar de que se muestreó el triple de esculturas, la incidencia de este material únicamente corresponde a $0.3 \%$. En los siglos XIX y XX, aunque el número de esculturas muestreadas es reducido, en ningún caso se identificó Zea mays. A partir de estos datos se puede deducir que el uso de la caña de maíz para la producción de esculturas tuvo su auge en los siglos XVI y XVII, decayendo a partir del XVIII. Aunque de manera general la escultura ligera se acostumbra denominar "escultura de caña", es evidente que en la mayoría de los casos este tipo de escultura tiene un soporte de colorín.

También fueron consultadas otras fuentes, que hacen referencia al trabajo con maderas en otros objetos como retablos, pinturas sobre tabla, y en los bastidores y marcos de pinturas de caballete, además en materiales de construcción.
El libro Introducción al estudio de la construcción práctica del Ingeniero Antonio Torres Torija, (1895: 50 y 51), ofrece un panorama de las características de las maderas relacionadas con su uso, e indica que para el trabajo en madera, se utilizaban diferentes especies:

Caoba [...] para la carpintería de muebles se utiliza en primer lugar; por ser la más fina [...] Fresno, para construcción de carruajes y pilotes en los cimientos [...] Cedro rojo, en México se usó mucho en la época de la Conquista, tanto en la viguería como en los cimientos y en la carpintería interior [...] Encino, su madera es de gran importancia en la construcción, ya que se utiliza como sostén [...] y se puede conservar en el agua, donde toma un color negro como el ébano. Pino, son las maderas más usadas en la Republica Mexicana. [...] se tienen diversas clases de pinos que se encuentran en las regiones altas [...] 1. Jalocote (Pinus patula) [...] se utiliza para puertas, ventanas y otras obras de interiores. 2. Oyamel (Abies religiosa) se emplea en techos. 3. Ocote (Pinus oocarpa) se utiliza en grandes planchas para sostener grandes pesos.

Aparentemente las maderas más utilizadas en arquitectura no eran las más comunes para esculturas, ya que la caoba se encontró sólo en una muestra del siglo XVII y el fresno en una del Xx. El cedro rojo se identificó en tres muestras del siglo XVIII y el encino en cinco muestras de los siglos XVII, XVIII y XIX. En lo que sí coincidimos con Torres Torija es en el hecho de que el pino es la madera más usada. Comparativamente se puede observar que tanto el Pinus patula como Pinus oocarpa son especies que se identificaron en las esculturas analizadas, sin embargo no se hace mención al Pinus ayacahuite ni al strobus, los cuales han sido de los más encontrados en las esculturas.

Herrera (2001: 200 y 201), en su artículo sobre el retablo sevillano, se refiere al pino de Flandes o borne empleado en el siglo XVIII en la retablística sevillana, preferido sobre cualquier otra especie debido a sus características, tanto para la estructura como para el ensamblaje de los retablos. Su uso se presenta en $86.1 \%$. En este aspecto, los materiales sevillanos coinciden con los mexicanos, en tanto que el pino es el material más utilizado, de manera genérica. Además, para las labores más delicadas de talla, como juguetes y sobre todo escultura, se reduce $54.8 \%$ su utilización, mientras que el cedro y el ciprés reúnen óptimas calidades para la escultura (ibidem: 203). En este artículo se ha denominado Pino de Flandes al que corresponde taxonómicamente con Pinus sylvestris.

En el texto de Vidal (2005: 36 y 39) encontramos la siguiente información:

[...] en el siglo xvı, la escultura en Castilla se labra en madera de tejo, nogal o pino, y algunas veces álamo o 
peral [...] Para el siglo xVII, la madera más comúnmente utilizada en la escultura española fue la de pino, sobre todo en Castilla [...] En Andalucia se utilizó el borne ( $P i$ nus sylvestris) y para las obras selectas, el cedro. Pero la madera más utilizada tanto para la construcción de retablos, como para la talla de la imaginería y para los bastidores de los lienzos, fue el Pinus ayacahuite, que abundaba en las sierras y bosques de la Nueva España, especialmente en el altiplano central en los valles de Puebla y Oaxaca.
El pino de Flandes o borne no se identificó en ninguna escultura, pero eso no significa que no se haya usado. Tal vez algunas de las maderas que sólo pudieron identificarse como Pinus sp., pertenecen a esta especie en particular, sin embargo, debido a las características de las muestras sólo fue posible identificar el género. El Pinus silvestris es una especie europea, no existe en América. Para hacer una escultura de Pinus silvestris, un escultor mexicano tendría que haber importado la madera.

Carrillo y Gariel (1946: 86 y 87) revisó y citó en su libro la trascripción de 1836 de los manuscritos de Die-

\section{Tabla 3. Clasificación taxonómica de las especies identificadas (ITIS) ${ }^{\mathbf{5}}$}

\section{GIMNOSPERMAS}

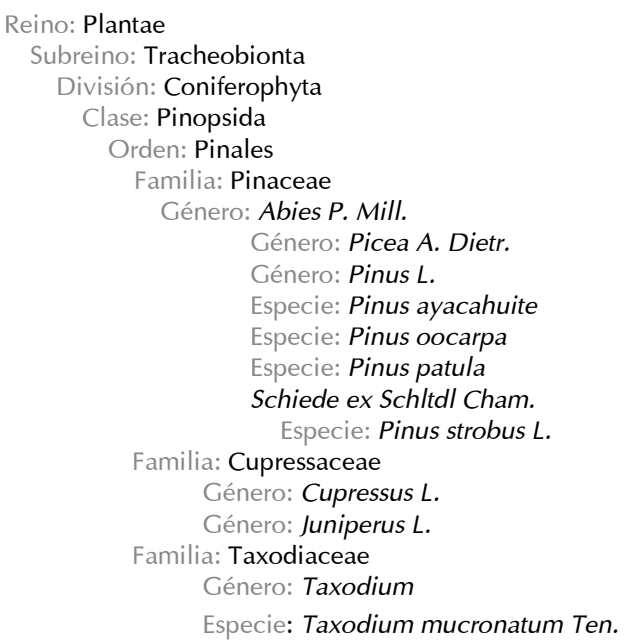

\section{ANGIOSPERMAS}

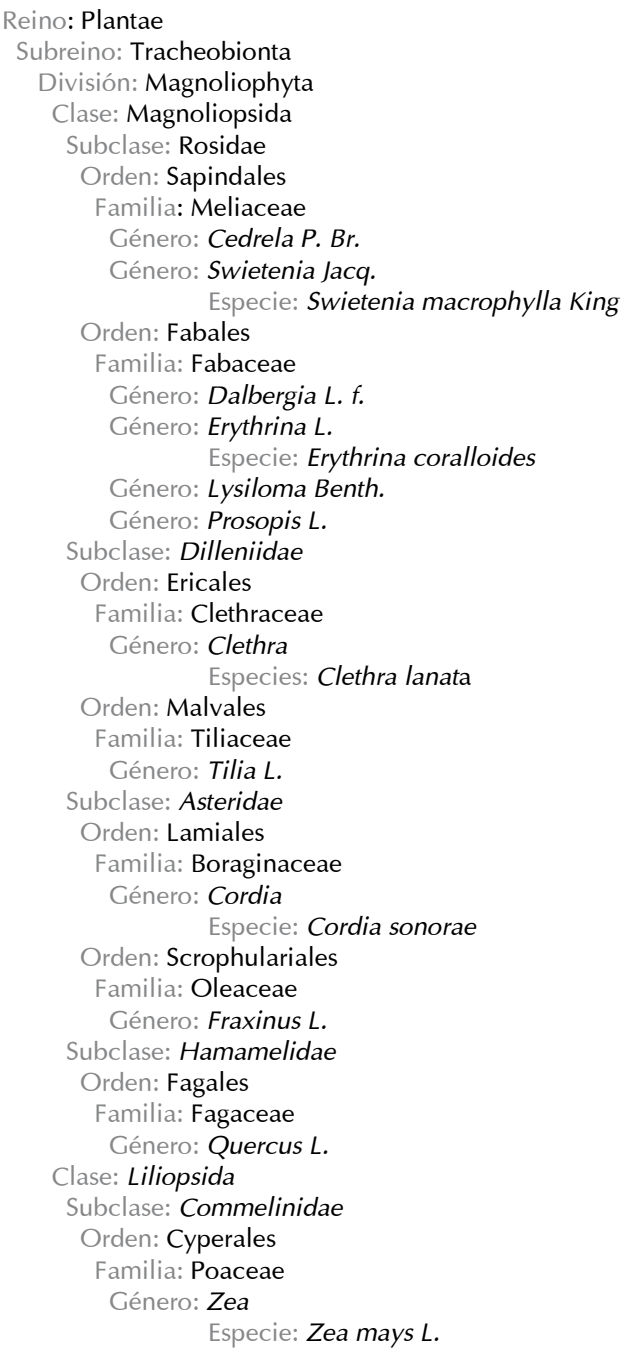

5 Integrated Taxonomic Information System (ITIS). Se establece como un estándar taxonómico mundial. Constituye un sistema de referencia y revisión de nombres científicos y comunes de organismos que se distribuyen principalmente en norteamérica, avalado por taxónomos especialistas. El Sistema Integrado de Información Taxonómica (SIIT *mx) corresponde a la interfaz mexicana de ITIS. México contribuye a este catálogo (el más grande del mundo) con más de 56000 nombres científicos, tanto de especies documentadas como existentes en el territorio nacional. Fuente www.conabio.gob.mx. 
go Muñoz Camargo (1947[1576]), en la cual describe las siguientes especies que eran muy utilizadas en la Nueva España: oyamel (Abies religiosa), sabino (Taxodium mucronatum), ayacahuite (Pinus ayacahuite), cedro (Cupressus thurifera y Cupressus benthami) y nogal (Juglans regia). Maquivar (1995: 91 y 94) también hace referencia a Muñoz Camargo al describir el ayacahuite y el cedro:

Ay otras maneras de pinos muy altísimos que no llevan resina, que son a manera de pinavetes y ansi lo davan de ser estos aunque no tienen llamarada lahevra que haze el pinavete el cual árbol Ilaman los naturales ayauhguahuitl, ques una madera blanca y muy tupida pesada y tiesa ques la que en esta tierra se labra para caxas y puertas y para hazer retablos y otras cosas de estima, y ansi es madera muy preciada $[. .$.

[...] De los árboles cipreses y cedros ay muy gran muchedumbre en las sierras nevadas de Huexotzinco y Calpan y en las faldas del volcán, son árboles altísimos y odoríferos $[\ldots]$

Como se puede observar, las principales especies de maderas citadas en la bibliografía, corresponden a los resultados obtenidos en esta investigación de los siglos XVI, XVII y XVIII, también se detectó, aunque en menor número, la presencia de otros géneros, tales como: Pinus strobus, Pinus patula, Juniperus sp., Quercus sp., Picea sp., Pinus oocarpa, Swietenia sp., Cedrela sp., Cordia sonorae, Clethra lanata, Taxodium mucronatum, y Dalbergia sp.

Para los siglos XIX y XX, tomando en cuenta que el universo con el que se trabajó es muy pequeño (11 piezas), se identificaron géneros no citados en la bibliografía consultada, tales como: Lysiloma sp. Prosopis sp. y Fraxinus $s p$. Sería conveniente realizar este tipo de análisis en un mayor número de esculturas, con el fin de tener un panorama más amplio sobre las especies utilizadas durante estos siglos.

Por último, en la Tabla 3, se muestra la taxonomía de las especies y géneros identificados con el fin de: primero, reducir los errores en el manejo de la misma que se encontraron en las fuentes antes citadas; $y$ segundo, aportar desde la biología aquellos conocimientos que por su sistematización e importancia ayudarán a que el complejo y diverso trabajo del profesional de la restauración tenga mayor certidumbre cuando necesite recurrir a otras disciplinas del conocimiento.

\section{Conclusiones}

Este trabajo comprueba que la Familia Pinaceae representa las maderas usadas con mayor frecuencia en la manufactura de estos bienes culturales, comprendidos entre los siglos XVI-XX, debido a sus características, durabilidad y permanencia en el tiempo; pero también demuestra que las especies del grupo de la Familia Cupressaceae, aun- que en menor proporción, se han utilizado a través de los siglos de manera frecuente.

A lo largo de este proyecto, se detectó que los procedimientos utilizados en el laboratorio para la toma de muestras y su posterior identificación, deben realizarse de manera sistemática y con un alto grado de especialización y conocimiento, con el objeto de que cada ejemplar pueda clasificarse con precisión, al menos identificando el género al que pertenece.

Estas investigaciones interdisciplinarias representan una aportación al conocimiento de los materiales empleados en la manufactura de los bienes culturales y colaboran con la determinación de los usos históricos de especies vegetales, dando por ende, mayor certidumbre y continuidad científica y técnica al trabajo de restauración y conservación de Bienes Culturales.

\section{Referencias}

Amador Marrero, Pablo

2002 Traza española, ropaje indiano. El Cristo de Telde y la imaginería en caña de maíz, España, M.I. Ayuntamiento de Telde, Gran Canaria.

Barajas-Morales, Josefina y Calixto León Gómez 1989 Anatomía de maderas de México: especies de una selva baja caducifolia, México, Publicaciones especiales, Instituto de Biología, UNAM.

Camacho Uribe, Daniel

1988 La madera estudio anatómico y catálogo de especies mexicanas, México, INAH.

Carrillo y Gariel, Abelardo

1946 Técnica de la pintura de Nueva España, México, Imprenta Universitaria.

De la Paz Pérez Olvera, Carmen

1993. "Anatomía de la madera de ocho especies con importancia en las artesanías del estado de Michoacán", en Acta Botánica Mexicana, septiembre, núm. 023. México, Instituto de Ecología. A. C.

De la Paz Pérez Olvera, Carmen y Lilia Patricia

Olvera Coronel

1981 "Anatomía de la madera de 16 especies de coníferas", en Boletín Técnico núm. 69, México, Instituto Nacional de Investigaciones Forestales, SARH.

De la Paz Pérez Olvera, Carmen, Lilia Patricia Olvera Coronel y L. G. Corral

1982 "Estudio anatómico de la madera de 26 especies de angiospermas de clima templado.", en Boletín Técnico núm. 91, México, SARH.

De la Paz Pérez Olvera, Carmen y Lilia Patricia Olvera Coronel 1990 "Características anatómicas de la madera de catorce especies de coníferas en La madera y su uso", en Boletín Técnico núm. 25, México, Instituto de Ecología y Universidad Autónoma Metropolitana.

Esquitín Lastiri, María del Carmen y José Eduardo

Antonio Silva Torres

1983 "Escultura policromada: aspectos histórico, tecnológi- 
co, científico y su relación con la restauración", tesis licenciatura en Restauración de Bienes Muebles, México, ENCRyMINAH.

Gómez, María Luisa

2002 La restauración. Examen científico aplicado a la conservación de obras de arte. 3a ed., Madrid, Instituto del Patrimonio Histórico Español (Cuadernos Arte Cátedra 34).

Herrera García, Francisco

2001 El retablo sevillano en la primera mitad del siglo XVIII. Evolución y difusión del retablo de estípites, Sevilla, Diputación de Sevilla, secc. Arte, Serie 1ํㅡㄹ (33): 74-119.

Huerta Crespo, Juana

1978 "Anatomía de la madera de 12 especies de coníferas mexicanas", en Boletín Técnico núm. 51, Subsecretaría Forestal y de Fauna, Dirección General de Investigación y Capacitación Forestales, México, SARH.

Maquívar, María del Consuelo

1994 "La Escultura de Vocacional" en México en el mundo de las colecciones de arte, vol. 3, Nueva España 1, Editora Ma. Luisa Saban García, México, SER, UNAM, CNCA, 301-325. 1995 El imaginario novohispano y su obra. 1a. ed. México, Instituto Nacional de Antropología e Historia.

\section{Resumen}

Esta investigación es el resultado del trabajo interdisciplinario que se realizó entre el Laboratorio de Biología y el Seminario-Taller de Restauración de Escultura Policromada (STREP) de la Escuela Nacional de Conservación, Restauración y Museografía (ENCRyM). Con base en la anatomía de las diversas especies de maderas, se identificaron 419 muestras pertenecientes a 140 esculturas, que fueron ordenadas cronológicamente desde el siglo $X V I$ al XX y que fueron restauradas en el STREP durante un periodo de 12 años (de 1998 a 2010).

\section{Palabras clave:}

Identificación de maderas, escultura policromada, maderas de esculturas restauradas ENCRyM.
Muñoz Camargo Diego

1947[1576] Historia de Tlaxcala, México, Publicaciones del Ateneo Nacional de Ciencias y Artes de México.

Olvera Coronel, Lilia Patricia

1985 "Descripción anatómica de la madera de siete especies del género Pinus", en Boletín Técnico núm. 126, México, SARH.

Rojas, Pedro

1963 "Las artes figurativas. La escultura", en Arte mexicano, época colonial, México, Instituto de Investigaciones Estéticas, UNAM, Hermes.

SIIT-Conabio

2010 Sistema Integrado de Información Taxonómica SIIT* mx, documento electrónico disponible en http:// www.conabio. com, consultado en mayo de 2010.

Torres Torija, Antonio 1895 Introducción al estudio de la construcción práctica, México, Oficina Tip, Secretaría de Fomento, 145. [Edición Facsimilar, compilador Pedro Paz. 1a. ed. Instituto Nacional de Antropología e Historia, 2001 México].

Vidal, T. Pablo

2005 "El retablo poblano: carpintería, talla y ensamblaje, 1555-1646", tesis licenciatura en Restauración de Bienes Muebles, México, ENCRyM-INAH.

\section{Abstract}

This investigation is the result of an interdisciplinary work between the Biology Laboratory and the Seminar / Workshop on Polychrome Sculpture Restoration (STREP for its spanish acronym) at the National School of Conservation, Restoration and Museography (ENCRyM Escuela National de Conservación Restauración y Museografía). Based on the anatomy of various wood species, 419 specimens were identified as belonging to 140 sculptures that were arranged chronologically from the sixteenth to the twentieth century and were restored by the STREP throughout 12 years of work, from 1998 until 2010.

\section{Keywords}

Wood identification, polychrome sculpture, wood from recovered sculptures, ENCRyM. 